\title{
Recurrent Criminal Behavior and Executive Dysfunction
}

\author{
Manuel Fernando Santos Barbosa ${ }^{1}$ and Luis Manuel Coelho Monteiro ${ }^{2}$ \\ ${ }^{1}$ Universidad de Porto \\ ${ }^{2}$ Instituto Superior de Ciencias de la Salud - Norte, Porto, Portugal
}

\begin{abstract}
Objective: To experimentally test the hypothesis that people who repeatedly participate in forms of non-violent crime exhibit an executive deficit detected in tests of high ecological validity, having changes in prefrontal functioning as neurophysiologic basis.

Participants and Methods: A battery to assess executive dysfunction was administered - the Behavioural Assessment of the Dysexecutive Syndrome (BADS) -to an experimental group of 30 inmates convicted of crimes against property (mean age $=39.3, S D=9.98$ ), and a control group of 30 (mean age $=32.7, S D=11.8$ ), all male.

Results: The group of recurrent inmates performed significantly worse than the control group in their global scores on the battery, as well as in the majority of subscales. Conclusion: Without removing from consideration the fact that sample size was not very large and, primarily, alerting ourselves to the dangerous hypothesis of a "frontal criminogenesis," the authors interpret criminal recurrence and resistance to penal measures in terms of the scarcity of control that individuals from the experimental group have over their behavior and its respective consequences.

Keywords: criminal recurrence; criminal behavior, neuropsychology, executive dysfunction
\end{abstract}

\begin{abstract}
Objetivo: Verificar experimentalmente la hipótesis de que las personas que participan repetidamente en delitos no violentos exhiben un déficit ejecutivo en pruebas de alta validez ecológica, y cambios en su funcionamiento prefrontal como substrato neurofisiológico. Participantes y Métodos: Se administró una batería para evaluar la disfunción ejecutiva - el Behavioural Assessment of the Dysexecutive Syndrome (BADS) -a un grupo experimental de 30 presos condenados por crímenes contra la propiedad (edad $=39,3$, DT $=9,98)$ y a un grupo control de 30 personas (edad $=32.7$, DT $=11.8)$, todos varones. Resultados: el grupo de presos reincidentes obtuvieron puntuaciones significativamente peores que las del grupo control en la batería, así como en la mayoría de las subescalas. Conclusión: sin dejar de considerar el hecho de que ninguna de las muestras era de tamaño muy grande y, especialmente alertando acerca de la hipótesis peligrosa de una "criminogénesis frontal", los autores interpretan le reincidencia criminal y la resistencia a las normas del código penal en términos de la falta de control que los individuos del grupo experimental tienen sobre su comportamiento y sus consecuencias respectivas. Palabras clave: reincidencia criminal, comportamiento criminal, neuropsicología, disfunción ejecutiva
\end{abstract}

Correspondence concerning this article should be addressed to F. Barbosa, Facultad de Psicología y Ciencias de la Educación, Universidad de Porto, Rua Dr. Manuel Pereira da Silva, 4200-392 Porto (Portugal). Phone: +351 22 6079700. Email: fbarbosa@fpce.up.pt 
Neuropsychological research about crime has focused on the search for evidence of neurological dysfunction that could contribute to understanding antisocial behavior in general, and of criminal behavior in particular, especially when that conduct is recurrent.

The majority of researchers that conduct neuropsychological studies of transgressors have primarily concentrated on the anterior regions of the brain, more specifically, areas of the prefrontal lobe. These areas are directly involved in the highest mental functions such as selective attention, working memory, action-planning competency, forethought, self-control and, at the most basic level, the regulation of the affectiveemotional life. Thus, the study of these functions has enormous relevance to understanding not only the behavioral changes associated with various pathologies, but also, although for different reasons, the conduct that deviates from social norms.

If we had to summarize the results of frontal lobe neuropsychological research, we would say that considered on the whole, studies suggest that there is neuropsychological dysfunction associated with crime in general, even if evidence of prefrontal dysfunction shows greater consistency among inmates incarcerated for violent crimes (Barbosa, 2001).

In other words, the results of neuropsychological and psychophysiological studies (Marques-Teixeira, 2000; Barbosa, 2001) tend to demonstrate that prefrontal dysfunction is characteristic of antisocial behavior in general - a marker for persistent, criminal behavior. This would explain the cases in which no significant psychobiological differences emerge between inmates who are psychopaths and those who are not, or between violent criminals and those convicted of non-violent crimes but have had prolonged antisocial careers. In effect, and according to Selby et al. (1998), the inmates' results indicate significant neurocognitive dysfunction in more than $60 \%$ of the measures used.

From the case of Phineas Gage (Harlow, 1868), to contemporary studies of the prefrontal cortex, a group of deficits has been revealed, today known as Frontal Lobe Syndrome (MacKinnon \& Yudofsky, 1986; Silver \& Yudofsky, 1987). It is characterized by a reduction in social aptitude, argumentative capability, symbolic understanding, forethought and worries about the behavioral consequences, as well as the loss of emotional resonance and increased impulsivity, distraction, emotional instability, among other changes.

Recently, abnormalities have been observed in decisionmaking, more markedly in the social sphere, in people with psychopathology incurred by orbitofrontal (Meyers et al., 1992) and ventromedial (Damásio, 1994; Saver \& Damásio, 1991) lesions. As Damásio (1994) described, these patients lose the capacity to generate a series of appropriate, alternative behaviors to respond to social situations and to anticipate the potential consequences of those alternatives, although there is no clear deficit in "pure" reasoning. In reality, evidence that orbitofrontal lesions do not produce a concrete deficit in reasoning seems to mistakenly imply that those lesions or dysfunctions do not exist (at least as identifiable using traditional evaluative instruments) in a considerable part of the recurrent criminal population-for example, in many of the inmates who are psychopaths (Hare et al., 1980).

Precisely for the above reason, and for its impact on the criminal subject's responsibility for his or her own actions, it is important to explore the hypothesis that there are prefrontal dysfunctions among recurrent criminals whose delinquent spree is marked by a precocious beginning and by the frequent practice of criminal acts (i.e., in which antisocial behavior is more pronounced). If they exist, these dysfunctions would restrict the available degrees of freedom to behave alternatively to crime, given that the prefrontal cortex determines the executive functions of the brain.

The term "executive functions" describes a group of mental capacities that allow an individual to define objectives, anticipate potential consequences, design plans of action, initiate mental and behavioral operations from motivation, control one's own actions, exhibit cognitive flexibility and organize behavior over time and space (GrothMarnat, 2000; Pineda, 1996; Pineda, Cadavid \& Mancheno, 1996; Stuss \& Benson, 1986; Weyandt \& Willis, 1994).

To evaluate executive functioning is a particularly problematic task due to the lack of methodological consensus, and the short supply of specific instruments. Also, the devices for neuropsychological evaluation that have been used for this purpose are of an excessively artificial and structured nature. They do not conveniently reflect the demands of real life where the dysfunctions are felt.

Recently, new instruments have emerged that combine a solid theoretical foundation with adequate psychometric and ecological validity. The Behavioural Assessment of the Dysexecutive Syndrome (BADS) is one of the instruments that systematically uses everyday tasks as a way of evaluating the executive functions (Wilson, Alderman, Burgess, Emslie, \& Evans, 1996). The battery was developed in response to the need for neuropsychological instruments that are more sensitive, valid and reliable in this area, at the same time overcoming the deficiencies associated with conventional tests. In spite of its relatively recent development, according to various researchers (e.g., Wilson et al., 1998; Crawford, 1998; Crawford et al., 2000; Groth-Marnat, 2000; Norris \& Tate, 2000), this battery shows a promising potential for responding to the aforementioned needs.

At the same time, this battery is particularly efficient at detecting subtle difficulties with the planning and organization of actions, especially in cases of people for whom cognitive capacity seems to be preserved for well-structured situations (Spreen \& Strauss, 1998), as seems to be the case for certain previously-mentioned groups of inmates, which might not have been detected by conventional tests. 
By using the BADS to neuropsychologically evaluate inmates, we tried to advance beyond the number of relatively disorganized studies that have suggested that there is a prefrontal deficit in this population. We pointed to the global evaluation of executive functioning in a subgroup of this population - recurrent criminals - because the effects of those functions are subtler. This new instrument allowed us to predict the impact of dysfunctions that will eventually be detected in the activities of everyday life.

This confirmed the hypothesis that recurrent inmates (who have been labeled as having antisocial tendencies) are characterized by executive deficits, evidenced by instruments that have high ecological validity. The confirmation of that hypothesis could contribute to explaining the difficulty within this group when it comes to planning, organizing, and regulating one's behavior to choose alternatives to crime.

\section{Method}

\section{Participants}

Two groups of 30 participants were evaluated, all male. One was the control group (CG), and the other the experimental group (EG).

The EG was composed of recurrent inmates convicted of non-violent crimes (primarily crimes against property), between the ages of 23 and $70(M=39.3, S D=9.98)$ from two different prison facilities in the northern region of Portugal. They all had at least two prior convictions $(M=$ 3.0) that required jail-time.

The article 75 of the Portuguese Penal Code defines recurrence as having committed a crime punishable by serving at least 6 months in prison, after having been previously convicted of a similar crime with a minimum sentence of 6 months, with no more than five years between the two convictions (excluding the duration of the sentence itself). Nevertheless, for the purpose of composing the experimental sample, those judicial-penal criteria were altered: inmates were considered eligible to participate in the study if they had committed two or, preferably, more voluntary crimes, punishable with a prison sentence. Any duration of prison sentence qualified, regardless of whether or not that sentence was fully, and effectively served, or whether there were alternative means of punishment applied. That change was justified by the fact that the scientific qualifications are not subject to judicial criteria. In fact, the previously-described antisocial tendency does not necessarily depend upon the kind of punishment applied or upon any temporal criteria, which are dogmatic and therefore difficult to support in science.

As for the CG, that group was composed of 30 men between the ages of 19 and $67(M=32.7, S D=11.8)$ from neighborhoods of the Oporto region and/or recruited from the Initial Professional Training Centers of the National
Institute for Employment and Professional Training. This group was selected to ensure the best possible matching of the samples in terms of academic qualifications (obligatory level of education or less), and socioeconomic background (lower or lower-middle class).

In both groups, cases of physical or sensory handicap, brain lesions, psychopathology, drug addiction and mental retardation were controlled (eliminated). The control condition was ensured by conducting a semi-structured, diagnostic interview with each CG participant, in which the Mini-Mental State Examination was also administered. Participants' information was checked according to information provided by the technical staff, and through authorized examination of individual records (only, of course, in the case of the inmates).

All participants were informed of the nature and objectives of the study, and participation in all neuropsychological tests was voluntary.

\section{Materials}

In order to evaluate executive dysfunction, the Behavioural Assessment of the Dysexecutive Syndrome (BADS) was used, which is a neuropsychological battery of essentially manipulative tests developed by Wilson and his collaborators (Wilson et al., 1996).

The BADS is divided into six subtests with tasks that emulate real-life activities, conceived in order to diagnose the existence of a deficit in general executive functioning, or in specific types of executive functioning. It is especially sensitive to the capacities affected by problem-solving skills, as well as planning and intentional organization of behavior over prolonged periods of time. More specifically, the subtests in the battery allowed us to assess: correct response to a rule of conduct and adaptation as a function of changing environmental contingencies; planning one's actions in order to problem resolution; anticipating the consequences, organizing one's actions across time and space aiming at specific goals; emotional, behavioral and cognitive changes, or changes in motivation, which are associated with frontal dysfunction.

To avoid potential cognitive deficits, we applied the Mini-Mental State Examination (Folstein, Folstein, \& McHugh, 1975).

\section{Procedure}

After obtaining informed consent, semi-structured, diagnostic interviews were employed, always one-on-one, in which data was collected to characterize the participants and the Mini-Mental State Examination was administered.

The BADS was administered during a second one-onone session to all subjects of the EG and the CG, and always by the same psychologist (specially trained). That session, dedicated exclusively to administering the BADS, was 
carried out just a few days later for the control group. The duration of data collection sessions varied from forty minutes to one hour, depending on individual performance.

In administering the battery, all directives described in the BADS manual were rigorously obeyed and the subscales were applied in the following order.

1. Rule Shift Cards: evaluated the ability to change an established response pattern using familiar materials. In the first part, a response pattern is established according to a simple rule. In the second part, the rule is altered and participants have to adapt their behavioral responses, inhibiting the original response pattern.

2. Action Program: this is designed to test the ability to solve practical problems. There is an object that must be moved from one place to another, but the resolution of that problem can only be achieved through the conveniently-planned use of various other materials, which were equally distributed to participants.

3. Key Search: is designed to test strategies of action. Analogous to whatever common problem, subjects are invited to demonstrate how they would find a lost object in a field, and their strategy of action is evaluated according to its adjusment and the probability that it would succeed.

4. Temporal Judgment: this test includes four questions that evaluate one's capacity to foresee or estimate how much time, on average, it takes to fulfill various tasks, events, or day-to-day activities.

5. Zoo Map: is a test of action planning. It gives information about the ability to plan a trip to visit six of twelve possible sites within a zoo. Subjects must first do this in an open situation, with an undetermined purpose; little external structure to behavior is provided. Then, they have to plan it in a situation that involves simply following a concrete behavioral strategy, externally imposed.
6. Modified Six Elements: this is a test of planning, temporal organization of tasks and self-assessment of success. It is a simplified version of the original test by Shallice and Burgess (1991) in which subjects had to organize six tasks and plan their time to execute them all in ten minutes.

After proceeding through the sequence of subscales, a score was calculated for each (0-minimum to 4-maximum) in accordance with evaluation criteria provided in the manual ( $c f$. Wilson et al., 1996), and the global score on the battery was derived from the sum of the partial scores (0-minimum to 24-maximum). Considering that this experimental study was comparative (between-group), the conversion of individual scores into standard scores was avoided; instead, we worked directly with "profile" results. Apart from the statistical measures of central tendency and distribution, (means and standard deviations), we proceeded to apply parametric statistics (t-test) in order to estimate betweengroups differences. Although normality and homogeneity were not confirmed by the distribution of the majority of the results, the parametric tests were considered to be sufficiently robust to perform an adequate statistical analysis, according to Lindman's (1974) arguments.

For the statistical treatment of our data, we used Statistica software (version 6) by Statsoft.

\section{Results}

The presentation of the results will begin with partial scores collected for each subscale, and will conclude with the global results.

\section{Partial Scores}

The means and standard deviation of the results were calculated for each subscale and for each group, estimating the statistical significance of the differences using a $t$-test. The results obtained are presented in Table 1.

Table 1

Means, Standard Deviations, $t$ Values and Effect Size (Cohen's d) of the Partial Results of the Control and Experimental Groups in each of the 6 BADS Subtests

\begin{tabular}{|c|c|c|c|c|c|c|}
\hline \multirow{2}{*}{ BADS Subscales } & \multicolumn{2}{|c|}{ Control Group } & \multicolumn{2}{|c|}{ Experimental Group } & \multirow[b]{2}{*}{$t$ value } & \multirow[b]{2}{*}{$d$} \\
\hline & $M$ & $S D$ & $M$ & $S D$ & & \\
\hline Rule Shift & 3.30 & 0.88 & 2.27 & 1.48 & $3.28 * *$ & 0.85 \\
\hline Action Program & 3.67 & 0.80 & 3.43 & 0.77 & 1.15 & - \\
\hline Key Search & 2.57 & 1.04 & 1.07 & 0.74 & $6.44 * *$ & 1.66 \\
\hline Temporal Judgement & 1.67 & 0.80 & 1.23 & 0.77 & $2.13 *$ & 0.55 \\
\hline Zoo Map & 3.20 & 0.81 & 1.97 & 0.96 & $5.38 * *$ & 1.39 \\
\hline Modified Six Elements & 3.83 & 0.46 & 3.10 & 0.92 & $3.89 * *$ & 1.00 \\
\hline
\end{tabular}

Note. Statistical power is always $>.80$ for $\alpha=.05$, except in the Temporal Judgement Test, when it has a value of .44 $* p<.05$. ** $p<.01$. 
Table 2

Means, Standard Deviations, $t$ Values and Effect Size (Cohen's d) of the Time needed to Perform each BADS Subtest in the Control and Experimental Groups

\begin{tabular}{|c|c|c|c|c|c|c|}
\hline \multirow{2}{*}{ Timed BADS subscales (seconds) } & \multicolumn{2}{|c|}{ Control Group $(n=30)$} & \multicolumn{2}{|c|}{ Experimental Group $(n=30)$} & \multirow[b]{2}{*}{$t$ value } & \multirow[b]{2}{*}{$d$} \\
\hline & $M$ & $S D$ & $M$ & $S D$ & & \\
\hline Rule Shift & 29.77 & 8.14 & 49.33 & 17.46 & $-5.56 * *$ & 1.44 \\
\hline Action Program & 71.40 & 43.67 & 115.63 & 69.13 & $-2.96 * *$ & 0.77 \\
\hline Key Search & 49.90 & 24.25 & 85.40 & 53.60 & $-3.30 * *$ & 0.85 \\
\hline Zoo Map & 188.73 & 87.16 & 332.77 & 146.85 & $-4.62 * *$ & 11.9 \\
\hline
\end{tabular}

Note. statistical power is always $>.08, \alpha=.05$.

$* * p<.01$.

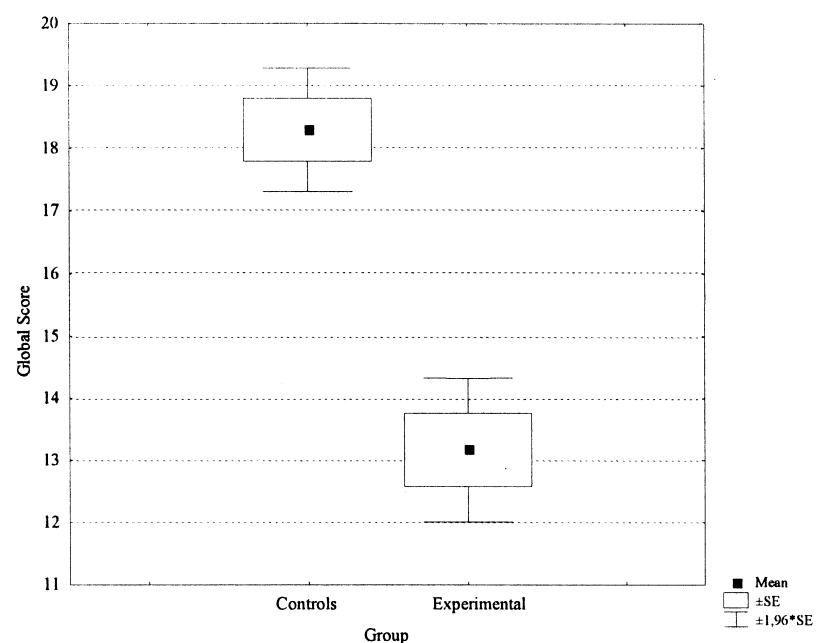

Figure 1. Means and standard error of the Control and Experimental groups' results.

As may be observed by an analysis of the table, the group of recurrent inmates was less successful than the control group in all subscales of the battery without exception. The differences in performance were revealed to be statistically significant in all subtests except for the second - action program.

As for the time it took to execute each section, for the subtests in which time was taken into account $(1,2,3$, and 5 ), we obtained the results presented in Table 2.

In this way, it was verified that the group of inmates needed significantly longer periods of time compared to the control group to execute the tasks of all the subscales where time was taken into consideration as a factor in their performance.

\section{Global Results}

The mean values, standard deviation and standard error were once again calculated for the global results of each group, and for the global time it took to perform each of the timed tests.

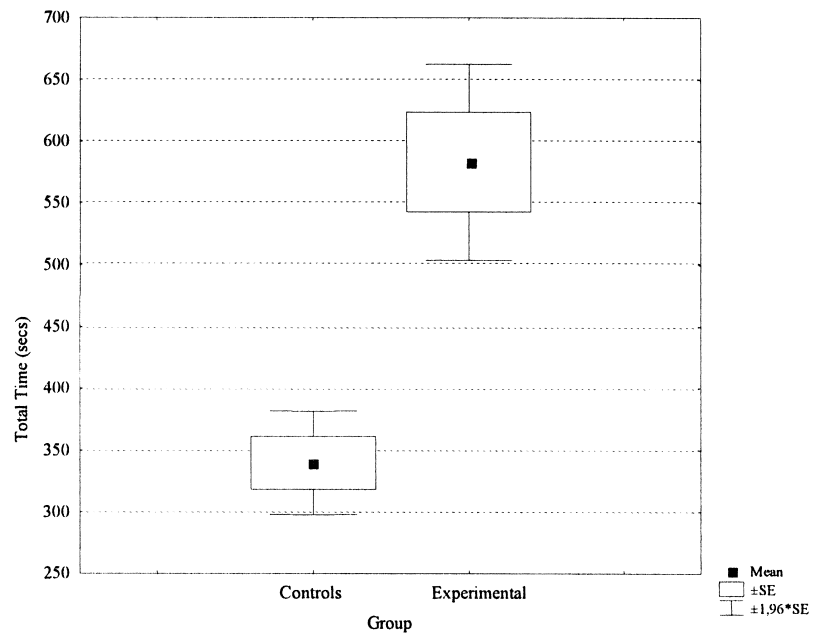

Figure 2. Means and standard error of the total time needed (in seconds) by the Control and Experimental groups to perform subscales.

In the analysis of Figures 1 and 2, it was observed that the global result obtained for the group of inmates $(M=13.17$, $S D=3.24$ ) was clearly lower than that of the control group $(M=18.30, S D=2.76)$, the difference being highly significant $(t(58)=6.61, p<.01$, Cohen's $d=1.71)$. Also, the time it took to complete the subscales differs with equal statistical significance $(t(58)=-5.31, p<.01$, Cohen's $d=$ $1.37)$, in favor of the control group $(M=339.80, S D=117.22$ vs. $M=583.13, S D=221.95$ in the EG). In both cases the statistical power observed is 1.00 for $\alpha=.05$.

\section{Discussion}

This study joins the scarce biopsychological research that has recurrent criminality as its primary object of study. Also, it is distinctive in that it studied perpetrators of minor crimes, for which it is more complex and controversial to confirm neuropsychological dysfunction.

Furthermore, it is unique in that it used a device with high ecological validity and that was specially designed to evaluate 
executive dysfunction - the BADS - which was chosen for three primary reasons. First, it has virtually no verbal content, so it is not compromised by cultural bias and is easily transferable to research in other cultures. Second, studies of validity conducted in clinical groups (psychopathology and prefrontal lesioning) demonstrated that performance on the battery is strongly correlated with the evaluations filled out by subjects' relatives, confirming that the results of the BADS are sensitive to executive deficit and are good indicators of the daily problems encountered by people with prefrontal lesion or dysfunction (Wilson et al., 1996). Last, an independent study about the ecological, construct, and concurrent validities of the BADS compared to other conventional tests of executive functioning has demonstrated that the results of that battery are significantly correlated with the results of conventional tests and are comparable to those tests as far as distinguishing individuals with and without cerebral lesions (Norris \& Tate, 2000). In reality, the BADS has demonstrated a superior ecological validity, proving it has a better ability to predict the competencies that are necessary to function in a real context (Norris \& Tate, 2000).

Overall, the results obtained through the BADS in the present study reveal that the recurrent criminals who were studied suffer from executive dysfunction, by comparing them to a sample of individuals whose conduct remains within socially acceptable patterns.

A closer analysis allows us to conclude that the performance of the experimental group was significantly deficient in all subtests, except for action program. However, the time taken to complete that subtest for the criminals, similar to what occurred in the other subtests, was significantly higher than in the control group, and they obtained worse results. Their weak performance in various subtests suggests the increased difficulty that recidivist criminals have with learning rules of behavior and, more importantly, in the substitution of those rules with others when the first prove inefficient. Those same difficulties are felt in the effective planning of a course of action, as well as in monitoring and regulating one's own behavior. This low performance also shows that these individuals have less of an ability to utilize external references to orient their behavior. In truth, not only do they tend to fail to carry out concrete, behavioral strategies in highly structured situationsin which they ought to respect externally imposed normsthey fail most of all when they have to spontaneously plan their behavior in minimally structured contexts.

In light of this set of results, can we affirm that executive dysfunction lies within the etiology of chronic forms of transgressive behavior? Is that data enough to assert the existence of frontal lobe "criminogenesis?"

Obviously, frontal "criminogenesis" should only be alleged with the utmost caution, given that criminal behavior is, by nature, heterogeneous and that it is determined by an array of factors. It is easy to accept the notion that the neuropsychological factors involved in crimes against property differ from those involved in violent crime. Along those lines, neuropsychological correlates may differ in recurrent criminality and primary criminality, or in antisocial behaviors that are not actually criminal. We concur with Marques-Teixeira (2000) in his suggestion that the designation antisocial should be reserved for individuals with a stable tendency toward behaviors that are contrary to the social order. Those behaviors constitute criminal actions when, as well as being socially reprehensible, they violate judicial-penal rules. If, here, we use the notion of antisocial and its varieties indiscriminately, we do so because it is more important in this case to emphasize the recurrence of those acts, than to delineate the differences between them, or between the people who carry them out.

The direction of causality between neurobiological factors and criminal behavior is another issue. The majority of studies have been developed under the general belief that neurobiological conditions precede crime and not the inverse, which is clearly disputable. Many authors argue that the risk associated with a life of crime may be responsible for a greater incidence of cerebral lesions among the criminal population, particularly at the frontal area, given the higher susceptibility of this region of the brain (for reference, see Barbosa, 2000).

It would be impossible to confirm that an executive deficit found in recurrently transgressive individuals is the primary cause of criminal recurrence, or that adopting highrisk behaviors brought on lesions of the neuroanatomical substrate. However, the empirical data and research methodology employed (excluding subjects whose clinical records indicated or caused us to suspect of lesions or neuropathology, and excluding participants with bellownormative mental and cognitive aptitudes), allows us to insist that the executive deficit found does play a role at a functional level.

In any case, be it of a functional or structural etiology, or both, this behavioral phenomenon shares many common denominators with the Dysexecutive Syndrome (DS). The term Dysexecutive Syndrome (Baddeley, 1986), refers to a similar clinical-frame to what was previously described as Prefrontal Lobe Syndrome, characterized by disorder in the planning and organizing of actions, problem-solving, and selective attention. In cases of pathology, lesioning or cerebral dysfunction, the DS is considered one of the principle areas of neurocognitive deficit that impedes the full functional recuperation and the possibility of recovering a socially responsible, independent, well-adapted, and wellspent life. The people affected by this syndrome tend to show high levels of impulsivity, distraction, difficulty using environmental feedback to regulate their behavior, and they tend to behave in a way that is poorly adjusted to social situations.

For those reasons, executive dysfunction also poses certain limitations to how people respond to rehabilitation and resocialization programs (Wilson et al., 1996). Being 
certain of the statistical association between recurrent, delinquent behavior and executive deficit, according to Wilson and his collaborators (1996), that deficit could contribute to explaining the increased resistance of these individuals to resocialization programs. Consequently, alterations in prefrontal functioning should not be excluded from biopsychological advances where, articulated by other factors, they favor conceptual developmental models that are more integrated and, thus, more able to explain the perseverance of certain individuals in criminal patterns. In other words, without meaning to exclude other psychological and social factors, it is plausible that, among other effects of executive deficit, the scarcity of mental control exhibited by this group of people over their behavior, their reduced flexibility and self-control, and their difficulty to conceive behavioral consequences, may result in maladjusted behaviors, some of which are contrary to the law.

\section{References}

Baddeley, A. (1986). Working memory. Oxford, UK: Clarendon Press.

Barbosa, F. (2000). Reincidência criminal: 20 anos de investigação neuropsicológica. Saúde-Mental, 2, 29-38.

Barbosa, F. (2001). Psicofisiologia do comportamento criminal reincidente: índices periféricos autonómicos. Saúde-Mental, 3, 19-32.

Crawford, J. (1998). Assessment of attention and executive function. [Special issue]. Journal of Neuropsychological Rehabilitation. Psychology Press.

Crawford, J., Blackmore, L., Lamb, A., \& Simpson, S. (2000). Is there a differential deficit in fronto-executive functioning in Huntington's disease? Clinical Neuropsychological Assessment, 1, 4-20.

Damásio, A. (1994). O erro de Descartes (17 th ed.). Sintra, Portugal: PEA.

Folstein, M., Folstein, S.E., \& McHugh, P.R. (1975). "Mini-Mental State," a practical method for grading the cognitive state of patients for the clinician. Journal of Psychiatric Research, 12, 189-198.

Groth-Marnat, G. (2000). Neuropsychological assessment in clinical practice: A guide to test interpretation and integration. Hoboken, NJ: Wiley.

Hare, R., Frazelle, J., Bus, J., \& Jutai, J. (1980). Psychopathy and structure of primary mental abilities. Journal of Behavioral Assessment, 2, 77-88.

Harlow, J. (1868). Recovery from the passage of an iron bar through the head. Publications of the Massachusetts Society, 2, 327-347.

Lindman, H. (1974). Analysis of variance in complex experimental designs. San Francisco: Freeman.

MacKinnon, R., \& Yudofsky, S. (1986). Psychiatric evaluation in clinical practice. New York: Lippincott.

Marques-Teixeira, J. (2000). Comportamento criminal: perspectiva biopsicológica. Linda a Velha, Portugal: Vale \& Vale.
Meyers, C., Berman, S., Scheibel, R., \& Hayman, A. (1992). Case report: Acquired antisocial personality disorder associated with unilateral left orbital frontal lobe damage. Journal of Psychiatry and Neuroscience, 17, 121-125.

Morgan, A., \& Lilienfeld, S. (2000). A meta-analytic review of the relation between antisocial behavior and neuropsychological measures of executive function. Clinical Psychology Review, 20, 113-156.

Norman, D., \& Shallice, T. (1980). Attention to action. Willed and automatic control of behavior. San Diego: University of California.

Norris, G., \& Tate, R. (2000). The Behavioural Assessment of the Dysexecutive Syndrome (BADS): Ecological, concurrent and construct validity. Neuropsychological Rehabilitation, 10, 3345.

Pineda, D. (1996). Disfunción ejecutiva en niños con trastornos por deficiencia atencional con hiperactividad (TDAH). Acta Neurológica Colombiana, 12, 19-25.

Pineda, D., Cadavid, C., \& Mancheno, S. (1996). Características de la función ejecutiva en niños con deficiencia atencional e hiperactividad (DAH). Acta Neurológica Colombiana, 12, 187196.

Saver, J., \& Damasio, A. (1991). Preserved access and processing of social knowledge in a patient with acquired sociopathy due to ventromedial frontal damage. Neuropsychologia, 29, 12411249.

Selby, M., Airy-Eggertsen, A., \& Laver, G. (1998). Comparison of neuropsychological test performance in forensic and nonforensic populations. American Journal of Forensic Psychology, 16, 45-58.

Shallice, T., \& Burgess, P. (1991). Deficits in strategy application following frontal lobe damage in man. Brain, 114, 727-742.

Silver, J., \& Yudofsky, S. (1987). Aggressive behavior in patients with neuropsychiatric disorders. Psychiatry Annals, 17, 367370.

Spreen, O., \& Strauss, E. (1998). A compendium of neuropsychological tests. New York: Oxford University Press.

Stuss, D., \& Benson, D. (1986). The frontal lobes. New York: Raven Press.

Weyandt, L., \& Willis, W. (1994). Executive function in schoolaged children: Potential efficacy of tasks in discriminating clinical groups. Developmental Neuropsychology, 10, 2738.

Wilson, B., Alderman, N., Burgess, P., Emslie, H., \& Evans, J. (1996). Behavioural Assessment of the Dysexecutive Syndrome (Bads). London: Thames Valley Test Company.

Wilson, B., Evans, J., Emslie, H., Alderman, N., \& Burgess, P. (1998). The development of an ecologically valid test for assessing patients with a dysexecutive syndrome. [Special issue]. Journal of Neuropsychological Rehabilitation. Psychology Press.

Received January, 12, 2007 Revision received December, 12, 2007 Accepted December, 17, 2007 